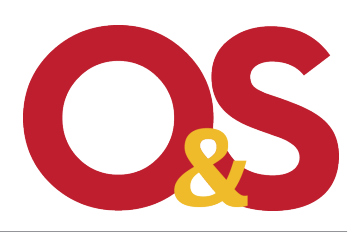

Revista Organizações \& Sociedade

2020, 27(92), 95-112

\title{
Metamorfoses de um discurso: carreiras sem fronteiras e o novo espírito do capitalismo
}

(1) Autor(es) 2020

DOI 10.1590/1984-9270925

ISSN 1984-9230

Metamorphosis of a Discourse: Boundaryless Careers and the

New Spirit of Capitalism

www.revistaoes.ufba.br

NPGA, Escola de Administração

Universidade Federal da Bahia

Recebido: 23/10/2017

Filipe Augusto Silveira de Souza ${ }^{a}$

Aprovado: 10/10/2018

Ana Heloísa da Costa Lemos ${ }^{b}$

Marcelo Almeida de Carvalho Silvac

aFundação Getúlio Vargas, São Paulo, SP, Brasil

'Pontifícia Universidade Católica do Rio de Janeiro, Rio de Janeiro, RJ, Brasil

Unniversidade Federal do Rio de Janeiro, Rio de Janeiro, RJ, Brasil

\section{Resumo}

A crise capitalista dos anos 1970 introduziu uma série de transformações que modificaram as formas de organização do trabalho. Essas mudanças foram compreendidas, por Boltanski e Chiapello (2009), como promotoras de um novo espírito para o capitalismo. Em consonância com essas alterações, o conceito de carreiras sem fronteiras emerge a partir dos anos 1990, trazendo em seu bojo a ideia de mobilidade interorganizacional, associada ao sucesso profissional. Adotado de maneira ampla, o conceito de carreiras sem fronteiras propõe, como orientação geral, a necessidade de o trabalhador desenvolver uma série de competências com vistas a adequar-se ao novo paradigma produtivo. Objetivamos, neste ensaio, refletir sobre o construto carreiras sem fronteiras, à luz da caracterização que Boltanski e Chiapello (2009) fazem da fase atual do capitalismo. Defendemos que o conceito de carreiras sem fronteiras serve como instrumento de mobilização da força de trabalho, contribuindo para ressignificar, sob a forma de autonomia e liberdade de escolha, a precariedade do trabalho sob esse novo paradigma. Apesar de seus aspectos controversos, o referido conceito vem se tornando referência no debate atual acerca da inserção no mundo do trabalho, o que justifica a importância desta discussão.

Palavras-chave: Carreira; Carreiras Sem Fronteiras; Espírito do Capitalismo; Discurso.

\section{Abstract}

The capitalist crisis of the 1970s introduced a series of transformations that modified the forms of work organization. Boltanski and Chiapello (2009) understood these changes as promoters of the new spirit of capitalism. In line with these changes, the concept of boundaryless careers emerged, starting in the 1990s, with the idea of interorganizational mobility associated with professional success. Broadly adopted, the concept of boundaryless careers proposes, as a general orientation, the need for the worker to develop a series of skills, in order to adapt to the new productive paradigm. We aim to reflect on the construct of boundaryless careers, in the light of Boltanski and Chiapello's (2009) characterization of the current capitalism. We argue that the concept of boundaryless careers serves as an instrument for the workforce mobilization, helping to re-signify, in the form of autonomy and freedom of choice, the precariousness of the working relationships established under the new paradigm. Despite its controversial aspects, this concept has become a reference in the current debate about the insertion in the world of work, justifying the importance of this discussion.

Keywords: Career; Boundaryless careers; Spirit of Capitalism; Discourse. 


\section{Introdução}

Fortemente influenciada pela sociologia crítica de Bourdieu, com quem trabalhou no início de sua carreira, a trajetória teórica de Luc Boltanski representa um crescente distanciamento da trilha bourdieusiana - "como em um êxodo, o ponto de onde parte é o ponto do qual foge" (Vandenberghe, 2015). A sociologia da crítica, desenvolvida pelo autor em parceria com Laurént Thévenot (Boltanski \& Thévenot, 1991, 1999), pode ser traduzida como uma tentativa de superação de uma premissa central subjacente à sociologia crítica bourdieusiana, segundo a qual "o único agente reflexivo é o sociólogo" (Vandenberghe, 2015, p. 30). Boltanski e Thévenot (1991) rejeitam, portanto, o distanciamento usualmente proposto entre o saber objetivo do cientista social e o saber leigo dos agentes ordinários (Celikates, 2012), ao mesmo tempo em que deslocam a escala de análise do nível macro (estruturas e mecanismos sociais) para o nível micro (modos de engajamento, justificação e ação individuais), sob influência da etnometodologia, do pragmatismo e da hermenêutica (Véran \& Vandenberghe, 2015).

É dessa forma que Boltanski e Thévenot (1991) caminham da sociologia crítica de Bourdieu, centrada no conflito e no condicionamento dos atores, para uma sociologia da crítica, na qual os indivíduos, promovidos à condição de agentes, se revelam capazes de articular criticamente suas pretensões de justiça, amparando suas justificações em convenções normativas denominadas cidades ou "cités" (Celikates, 2012), marca distintiva da sociologia pragmática francesa (Véran \& Vandenberghe, 2015).

Apesar dessa guinada analítica, em 0 novo espírito do capitalismo, Boltanski e Chiapello (2009) fazem dialogar ambas as sociologias: "o modelo de cités é reformulado, e o que era pano de fundo (o poder e a história) assume o primeiro plano. Com essa passagem da micro para a macrossituação, Boltanksi reencontra a verve política de Pierre Bourdieu" (Vandenberghe, 2015, p. 15). Cabe ressaltar que a retomada da dimensão do poder não implicou a adoção de uma abordagem ideológica ortodoxa, segundo a qual os indivíduos se veem sistematicamente incapazes de reconhecer seus interesses (Celikates, 2012); em seu lugar, Boltanski e Chiapello (2009, p. 33) propõem a ideologia como "conjunto de crenças compartilhadas, inscritas em instituições, implicadas em ações e, portanto, ancoradas na realidade". De especial importância para os autores é a dinâmica entre o capitalismo e seus críticos, de sorte que a apropriação seletiva da crítica emerge como elemento primordial no processo de renovação do aparato justificativo do sistema capitalista (Boltanski \& Chiapello, 2009).

Ao abordarem as mudanças ideológicas associadas às transformações do capitalismo nas últimas décadas, Boltanski e Chiapello (2009) elaboraram um retrato sociológico que buscou compreender o processo de formação histórica do capitalismo, não só o institucional, mas também o ideológico; para tanto mobilizaram uma abordagem pragmática que buscou desvelar o pano de fundo moral subjacente às distintas etapas do sistema capitalista (Freitas, 2013).

A expressão "espírito do capitalismo" é utilizada pelos autores para representar a ideologia que justifica o engajamento dos indivíduos ao sistema capitalista em diferentes momentos históricos. Incapaz de oferecer motivos para sua adoção convergente com os valores e interesses de trabalhadores e empresários, o sistema capitalista lançaria mão de ideologias capazes de justificar a aderência à sua lógica. Entretanto, quando da alteração das formas de acumulação capitalista, as crenças associadas à ideologia que fundamenta o espírito do capitalismo correspondente à fase em questão tornam-se obsoletas, demandando novas crenças adaptadas às formas de acumulação vigentes. Segundo os autores, este movimento aciona uma série de dispositivos ideológicos.

As mudanças ideológicas abordadas compreendem a emergência de novas noções de agente (free agent), de organização (organização sem fronteiras) e de ordem social (sociedade em rede), cuja legitimação passa pela construção de um novo espírito do capitalismo. Todavia, conforme destacam os autores, a construção de uma nova ideologia capaz de conferir sentido positivo às mudanças em curso na ordem capitalista não é um 
empreendimento trivial. Ao contrário, a construção desse novo espírito requer a enunciação de um "conjunto de crenças associadas à ordem capitalista que contribuem para justificar e sustentar essa ordem" (Boltanski \& Chiapello, 2009, p.42).

As crenças ou justificações necessárias para a adesão ao projeto capitalista são difundidas por meio de discursos empresariais, que se apresentam como um dos "principais espaços de inscrição do espírito do capitalismo" (Boltanski \& Chiapello, 2009, p. 83). Dessa forma, a análise do discurso empresarial permite apontar as transformações ocorridas nas formas de justificação para o engajamento no capitalismo. Boltanski e Chiapello (2009) comparam o discurso empresarial em dois momentos distintos, demonstrando como o discurso voltado para a administração por objetivos, predominante nos anos 1960, deu lugar ao modelo das empresas em rede e mais enxutas. Ao tratar das carreiras empresariais, os autores explicam como a valorização de uma modalidade de carreira linear, ascendente e segura nas décadas de 1960 a 1980 foi suplantada nos anos 1990 pela ênfase em trajetórias profissionais focadas na autogestão, no empreendedorismo individual e na flexibilidade, sem as garantias e seguranças das décadas anteriores.

O destaque dado pelos autores à emergência de novos argumentos ideológicos, capazes de ressignificar as transformações em curso na ordem capitalista, inspirou a reflexão crítica apresentada no presente trabalho acerca do construto carreiras sem fronteiras. Esse conceito, que emerge na década de 1990 em contraposição ao então dominante conceito de carreira hierárquica ou organizacional (Rosenbaum,1979; Wilensky, 1964), é entendido no presente artigo como uma das expressões do repertório discursivo mencionado por Boltanski e Chiapello (2009). Para os fins deste trabalho postulamos, portanto, que o construto carreiras sem fronteiras introduz novos esquemas interpretativos no campo dos estudos de carreiras que contribuem para legitimar 0 conjunto de mudanças objetivas no ambiente corporativo nas décadas de 1980 e 1990, materializadas nos múltiplos processos de reestruturação organizacional, na flexibilização interna e externa da mão de obra, e na desregulamentação trabalhista (Antunes, 2011). Em outros termos, entendemos que tal conceito cumpre a função ideológica de justificação e legitimação do capitalismo, em sua atual fase de acumulação. Sua gênese remete a um contexto pautado pelo agravamento da crise global do início dos anos 1970, reflexo, entre outros fatores, da crise do petróleo, da desvalorização do dólar e da crescente competitividade no mercado internacional, com repercussão negativa nos índices de produtividade e de lucratividade dos mercados. Coloca-se em xeque, consequentemente, a matriz produtiva de base taylorista-fordista, que implica o deslanche de estratégias de flexibilização da produção, das relações de trabalho e do capital (Harvey, 1992).

Diante do dinamismo do novo ambiente negocial, defendeu-se que os gigantes corporativos teriam que se adaptar para garantir sua sobrevivência (Kanter, 1989). Nesse cenário, as corporações puseram em marcha processos de reestruturação organizacional que resultaram na supressão de níveis hierárquicos, no enxugamento do quadro de pessoal, na externalização de funções e na reorganização de grandes firmas em "unidades de negócio autônomas" (Arthur, 1994, p. 300).

Foi diante desse quadro de transformações que o conceito de "organizações sem fronteiras" surgiu, no início da década de 1990. O termo, que teve a sua paternidade atribuída a Jack Welch, então CEO da General Electric (GE), sugere a necessidade de superação das fronteiras internas e externas das organizações em virtude de transformações sistêmicas (Hirschhorn \& Gilmore, 1992). Em 1993, o termo foi escolhido como tema da conferência da Academy of Management, o que contribuiu para a popularização do conceito na academia. A publicação do livro The boundaryless organization (Ashkenas, Ulrich, Jick \& Kerr, 1995) ampliou a difusão do termo, o que resultou em sua posterior reificação e incorporação ao debate em outros campos dos estudos organizacionais.

No ano de 1994, Robert DeFillippi e Michael Arthur promoveram um simpósio que traduziu a referida noção para o campo de estudo de carreiras, resultando na proposição de uma nova perspectiva - as carreiras sem fronteiras. Caracterizada por uma trajetória multidirecional (Baruch, 2004) que perpassa múltiplas organizações, tal perspectiva prescreve a necessidade de os indivíduos tomarem para si a gestão de sua carreira (Arthur \& Rousseau, 1996; Sullivan \& Arthur, 2006). As carreiras sem fronteiras têm servido de referência 
para o debate acerca das novas configurações de carreira em boa parte da literatura sobre o tema, que, ao considerar esse formato como o novo status quo, não tematiza o caráter ideológico do construto. Essa constatação reforçou o interesse em elaborar uma análise crítica do construto carreiras sem fronteiras, tendo como referência as considerações de Boltanski e Chiapello (2009). Esta crítica é apresentada no presente artigo em cinco seções, incluindo esta introdução. A seguir, elaboramos uma síntese das principais categorias que informam o debate de Boltanski e Chiapello (2009) acerca das mudanças no capitalismo que serviram de referência para a crítica ao conceito em questão; na terceira seção, discutimos, em linhas gerais, o desenvolvimento do conceito de carreira sem fronteiras bem como algumas críticas a ele endereçadas; a análise crítica do conceito de carreiras sem fronteiras é aprofundada na quarta seção e, na última parte, apresentamos as considerações finais do trabalho.

\section{Um novo espírito para o capitalismo}

De acordo com a interpretação de Boltanski e Chiapello (2009), as diferentes fases pelas quais passou o capitalismo demandaram diferentes formas de engajamento ao sistema, cada uma correspondente a um "novo espírito", expressão adotada pelos autores como referência à ideologia que justifica essa adesão. Assim, cada fase do sistema capitalista apresentou um espírito próprio, cujas características refletiram a ideologia vigente. Com vistas a fundamentar o argumento central da presente pesquisa, buscamos compreender as características do mais novo espírito do capitalismo; para tanto, julgamos pertinente apresentar os diferentes espíritos do capitalismo para que, por meio da comparação, as transformações sejam evidenciadas.

Convém observar, previamente à próxima seção, que diversas situações são submetidas a imperativos de justificação e, por conta disto, incorporam referências que apontam para convenções que se pretendem universais (Boltanski \& Thévenot, 1991; Boltanski \& Chiapello, 2009). O capitalismo, percebido como uma dessas situações, demandaria justificações que fazem referência a essas convenções, - chamadas de "mundos" ou "cidades" pelos autores - que fundamentam justificações exigidas por determinadas situações sociais, manifestando formas de explicação dos diferentes espíritos.

\section{Os diferentes espíritos do capitalismo}

De acordo com Boltanski e Chiapello (2009), o primeiro espírito do capitalismo remete aos escritos weberianos, datados do final do século XIX, e tem como principal ator social o burguês, dotado de características heroicas e empreendedoras. Nesse estágio é possível afirmar que o comportamento do empreendedor burguês é, de certa forma, contraditório, na medida em que procura associar "disposições econômicas inovadoras [com] posicionamentos domésticos tradicionais" (Boltanski \& Chiapello, 2009, p. 49). 0 capitalismo organiza-se numa forma de acumulação de base familiar patriarcal, de sorte que o trabalhador, em princípio livre para vender sua força de trabalho e tornar-se assalariado, está, ao mesmo tempo, vinculado à estrutura patriarcal da empresa familiar. Tal paradoxo reflete, em algum grau, certa fragilidade na forma de o capitalismo prover as motivações necessárias para o engajamento de trabalhadores subordinados ao patriarcado. Nesse contexto, a ideologia do bem comum, capaz de explicar o comprometimento dos atores necessários à constituição do capitalismo, evoca um "utilitarismo vulgar para justificar os sacrifícios exigidos pela marcha do progresso" (Boltanski \& Chiapello, 2009, p. 50).

A aparente incompatibilidade entre "lucro e moralismo, avareza e caridade, cientificismo e tradicionalismo familiar" (Boltanski \& Chiapello, 2009, p. 50) reflete as formas de justificação do primeiro espírito do capitalismo, ancoradas na ideia de "cidade mercantil". Aqui as convenções privilegiam a coordenação entre as ações "através da mediação de bens escassos, cuja aquisição é pretendida por todos" (Boltanski \& Thévenot, 1991, p. 19). A principal qualidade das pessoas seria o oportunismo: "detectar e aproveitar as oportunidades 
do mercado, desvinculados de qualquer laço pessoal e emocionalmente sob controle. Eles se conectam um ao outro através de relações de competição" (Boltanski \& Thévenot, 1991, p. 19). Ao mesmo tempo, a "cidade doméstica" enuncia que a grandeza da pessoa adviria da hierarquia baseada na dependência pessoal, uma vez que "o elo político entre os seres é visto como uma generalização do parentesco, baseando-se nas relações face-a-face e no respeito à tradição. A pessoa não pode, neste mundo, deixar de pertencer a um grupo, uma família, uma linhagem, uma posição" (Boltanski \& Thévenot, 1991, p. 17). No contexto empresarial, as relações humanas nessa cidade seriam estabelecidas de acordo com a recomendação, a geração de dependentes, a educação ou apresentação de um convite, estando baseadas na lealdade e no caráter.

Entre os anos 1930 e 1960, as cidades industrial e cívica mostrar-se-iam dominantes, sendo esta última marcada por um espírito de solidariedade segundo o qual os indivíduos abandonam "seus interesses particulares e se conduzem exclusivamente na direção do bem-comum" (Boltanski \& Thévenot, 1991, p. 18). A valorização do indivíduo resultaria de seu pertencimento ao quadro coletivo. Para assegurar a realização do bem comum, a cidade cívica alude a um soberano que estaria acima dos interesses individuais (Boltanski \& Thévenot, 1991), identificado com a figura do Estado de bem-estar social (Welfare State), concebido no pós-guerra.

A cidade industrial, também evocada na justificação do segundo espírito do capitalismo, identifica grandeza na eficácia e capacidade profissional. A empresa familiar do primeiro espírito perde espaço para a grande empresa burocrática. A partir dessa nova noção de empresa, na qual concepção e execução do trabalho são divorciadas, surge a dissociação das figuras do supervisor e do trabalhador, bem como do diretor e do próprio capitalista, dono do empreendimento.

Sob essas circunstâncias, ganha força o conceito de carreira como trajetória ascendente. Boltanski e Chiapello (2009) explicam que, devido ao gigantismo das empresas, surge a necessidade de planejamento de longo prazo, capaz de oferecer garantias ao trabalhador no âmbito da vida pessoal com a perspectiva de construção de uma carreira. Esses dispositivos constituiriam um ambiente de proteção aos empregados no interior da grande empresa. Entretanto, o crescimento e a verticalização da estrutura resultaram no monopólio decisório correspondente a sistemas administrativos autocráticos. A insatisfação dos executivos, segundo os autores, motivou a adoção de medidas de descentralização, de políticas de meritocracia e, em especial, de uma administração focada no atingimento dos objetivos.

Cabe destacar que a autonomia pretendida pelos executivos não tinha como intenção se opor à hierarquia, mas apenas renegociar as bases nas quais ela estava estabelecida. Desse modo, procurou-se deslocar, por exemplo, a antiguidade em favor do mérito e das responsabilidades diante dos objetivos a serem alcançados, como critérios de recompensa. Nota-se, assim, a maior ênfase nos valores da cidade industrial em detrimento daqueles da cidade doméstica. A administração por objetivos destaca-se, desta forma, como um conceito particularmente eficaz ao prever a concessão de uma espécie de autonomia tutelada, já que as especificações dos cargos permitem conceder uma autonomia com objetivos alinhados aos interesses da empresa. Contudo, a consecução desses objetivos não é possível sem que a empresa ofereça garantias ao trabalhador.

Nesse sentido a carreira hierárquica cumpre papel fundamental na ideologia do segundo espírito capitalista em, pelo menos, três aspectos. Em primeiro lugar, ao basear-se em aspectos meritocráticos, a carreira serve como régua para mensurar a eficiência dos gestores e oferecer um senso de justiça (Boltanski \& Chiapello, 2009). Em segundo lugar, o problema da falta de executivos pode ser contornado pela perspectiva de uma carreira delineada "com recrutamentos preventivos e estabelecimento de perfis de carreiras que possibilitem ir levando os iniciantes, gradualmente, ao nível de competências dos postos que exigem grandes responsabilidades. As carreiras motivam os executivos que se sentem reconhecidos em sua capacidade" (Boltanski \& Chiapello, 2009, p. 119).

A garantia demandada pelos trabalhadores pode ser assegurada por meio da "certeza de carreira aos executivos". A necessidade empresarial de conferir segurança ao trabalhador acabaria por Ihe oferecer uma 
estabilidade implícita, fora do contrato de trabalho, mas de conhecimento tanto do empregado quanto do capitalista. 0 segundo espírito do capitalismo é, assim, marcado por uma relação duradoura entre o trabalhador e a empresa que "só demite excepcionalmente e propicia carreiras vitalícias" (Boltanski \& Chiapello, 2009, p. 121).

0 terceiro espírito do capitalismo e a cidade por projetos

No âmbito da crise capitalista dos anos 1970, emerge a ideologia que corresponde ao novo espírito do capitalismo. A grande empresa transforma sua gestão, agora baseada na flexibilidade, na capacidade de adaptação às rápidas mudanças no mercado. Consequentemente, adota inovações que impactam a relação empresa-trabalho-Estado. De acordo com Boltanski e Chiapello (2009), essas inovações procuram apresentar benesses não apenas para as empresas, mas também para os trabalhadores, como forma de mobilizá-los. De maneira sucinta, as novidades orbitam em torno de três características principais: (i) da utilização de ferramentas gerenciais como reengenharia, uma forma de redução das estruturas organizacionais com o intuito de "enxugar" as empresas e capacitá-las às rápidas modificações exigidas pelo mercado; (ii) da organização produtiva baseada em vínculos temporários constituídos por redes, não só entre empresas, mas também entre trabalhadores; e (iii) da mobilização da força de trabalho por meio do trabalhador considerado "grande", que reúne qualificações diversas.

A ruptura com a estrutura burocrática e a rigidez hierárquica precedente evocam o preceito de liberdade, mas a autonomia tutelada oferecida pela administração por objetivos já não se mostra suficiente, demandando novas classes de liberdades. A proposta de libertação torna-se, então, na visão de Boltanski e Chiapello (2009), um dos principais atrativos do discurso empresarial dos anos 1990. Nessa direção, a metáfora da rede remete à noção de transgressão das barreiras de modo a formar conexões ou romper fronteiras entre cargos, departamentos, empresas e carreiras. Na busca pela superação da hierarquia, apregoa-se a superação de barreiras entre cargos, impactando o escopo de atuação do trabalhador, não mais limitado à sua função ou ao seu departamento, nem submetido "à autoridade de um chefe, pois todas as fronteiras podem ser transpostas pela virtude dos projetos" (Boltanski \& Chiapello, 2009, p. 122).

Na cidade por projetos, o trabalhador não depende mais de sua especialização, mas sim de atributos, tais como adaptação e flexibilidade, capazes de habilitá-lo a transitar entre as diferentes situações proporcionadas pelos diferentes projetos e adaptar-se a elas. Além disso, a atuação em projetos exige lidar com diferentes atividades e com a troca rápida entre elas, obrigando o trabalhador a desenvolver a polivalência funcional. Esse tipo de trabalhador, nomeado "grande", acumula também traços de autonomia, assunção de riscos e liderança, sendo capaz de contribuir no engajamento de pessoas (Boltanski \& Chiapello, 2009).

A convergência desses fatores evidencia a incapacidade da grande empresa de oferecer garantias ao trabalhador, especialmente em termos de estabilidade no emprego e oportunidades de carreira. A empresa se vê obrigada, então, a oferecer novas formas de garantia em substituição à carreira hierárquica. Boltanski e Chiapello (2009) explicam que a garantia oferecida pela empresa se pauta, a partir de então, pela possibilidade de desenvolvimento das habilidades desejadas na cidade por projetos.

A grandeza do trabalhador do terceiro espírito se manifesta, portanto, em sua capacidade de transitar de forma autônoma por diferentes organizações, engajando-se em projetos diversos. Diferentemente de seus antecessores, esses trabalhadores não devem aspirar a carreiras organizacionais hierárquicas, vistas, a partir de então, como obsoletas, mas a novos desafios e projetos. Dessa forma, "as pessoas não farão carreira, mas passarão de um projeto a outro, pois o sucesso em dado projeto Ihes possibilitará acesso a outros projetos mais interessantes" (Boltanski \& Chiapello, 2009, p. 125). 


\section{Carreiras sem fronteiras: 0 desenvolvimento de um conceito}

Definida como antítese da carreira organizacional (Arthur, 1994) ou, alternativamente, como uma "sequência de oportunidades de trabalho que ultrapassa as fronteiras de uma única organização" (DeFillippi \& Arthur, 1994, p. 116), o construto carreiras sem fronteiras deu novo fôlego às pesquisas desenvolvidas no campo (Pringle \& Mallon, 2003), apontando, entre outras coisas, as limitações inerentes ao escopo restrito de análise adotado até então, cujo foco privilegiava a dimensão intraorganizacional (Arthur \& Rousseau, 1996).

Um dos traços característicos dessa nova modalidade diz respeito à mobilidade interorganizacional; ao passo que em um primeiro momento privilegiaram-se as barreiras físicas (DeFillippi \& Arthur, 1994), subsequentemente dedicou-se especial atenção às barreiras psicológicas (Sullivan \& Arthur, 2006), associadas tanto ao sucesso na carreira quanto ao aumento da eficiência nas organizações (Arthur, 1994). Sob essas circunstâncias, as carreiras são equiparadas a repositórios de conhecimento das firmas (Bird, 1996), sendo as redes de relacionamentos individuais traduzidas nos termos de building blocks das redes organizacionais (Raider \& Burt, 1996). A dominância que tal perspectiva de carreira vem exercendo no campo, sobretudo nos estudos organizacionais, é de tal monta que chega a ser considerada por alguns como a representação de um novo status quo (Briscoe \& Hall, 2006).

0 referido construto remete, diretamente, à emergência de um cenário contemporâneo no qual novas formas organizacionais "determinam o mix de competências de carreira apropriadas para uma era particular" (Miles \& Snow, 1996, p. 97). À pressão exercida sobre as expectativas de carreiras, pela crescente flexibilidade dos sistemas de produção e do trabalho, soma-se a instauração de políticas econômicas neoliberais que restringem as oportunidades de carreira disponíveis aos indivíduos (Roper, Ganesh \& Inkson, 2010; Inkson, Gunz, Ganesh \& Roper, 2012).

A ruptura alardeada foi de tal magnitude que, ao refletir sobre a tarefa de desenvolver o quadro teórico relativo às carreiras sem fronteiras, Arthur e Rousseau (1996, p. 4) declararam ser "fácil e emocionalmente satisfatório, rejeitar uma lógica que já não [seria] mais verdadeira", fornecendo "uma tabula rasa de novas oportunidades". Na mesma linha, propôs-se que esse e outros conceitos emergentes de carreira representariam "uma grande mudança em relação ao que costumávamos conhecer no passado, talvez desde a construção das pirâmides e mesmo antes" (Baruch, 2004, p. 62).

A proposição das carreiras sem fronteiras traz em seu bojo um rol de características individuais julgadas essenciais para se ter sucesso na trajetória profissional e corresponde a uma visão voluntarista do trabalhador, definido como agente livre (Arthur, 1994) e investidor de seu capital de carreira, transmutando-o em empresário de si mesmo ou, em outros termos, em capitalista de carreira (Inkson \& Arthur, 2001). A adequada compreensão do processo de construção desse novo ator demanda maior aprofundamento de alguns de seus aspectos centrais, tarefa que se persegue a seguir.

Esculpindo o homem da nova era organizacional

A noção de carreiras sem fronteiras traz consigo uma forte ênfase na dimensão da agência, sobrevalorizando o potencial criativo individual, ainda que às custas da subvalorização de constrangimentos estruturais de toda sorte. Autoeficácia (Baker \& Aldrich, 1996), otimismo, resiliência (Higgins, Dobrow \& Roloff, 2010), inteligência (Arthur, Claman \& DeFillippi, 1995) e, sobretudo, autonomia individual (Baruch \& Reis, 2016) são apontadas por alguns autores como características demandadas dos trabalhadores no cenário atual, caracterizado não só pelos temas inovação e mudança, como pela flexibilização das fronteiras tanto das organizações quanto das carreiras (Hirschhorn \& Gilmore, 1992). Alega-se que as organizações, ao operarem em um ambiente econômico marcado por competitividade exacerbada, inovação tecnológica incessante e imprevisibilidade, não têm outro caminho a não ser adaptar a gestão dos seus negócios e recursos humanos 
às exigências dos novos tempos (Greenhaus, Callanan \& Direnzo, 2008). A crescente influência da dinâmica de mercado sobre as organizações impacta sobremaneira as carreiras, a começar pela desestruturação do mercado interno de trabalho e, portanto, dos sistemas tradicionais de carreira. Entre os efeitos colaterais a serem destacados está a maximização dos riscos a serem suportados pelos contingentes de trabalhadores que, por não disporem de volume significativo de competências que sejam, a um só tempo, valorizadas pelo mercado e transferíveis entre organizações, ficam mais próximos da condição de perdedores na nova ordem econômica (Cappelli, 1999).

A alegada dissolução das fronteiras hierárquicas, funcionais e geográficas (Hirschorn \& Gilmore, 1992) representantes das tradicionais guias que orientavam os indivíduos ao longo de suas carreiras, foi saudada por alguns pesquisadores do campo dos estudos de carreira como real oportunidade de os indivíduos trilharem 0 seu próprio destino profissional, independentemente da posição que ocupam no espaço social (Arthur \& Rousseau, 1996). Podem, assim, escolher em meio às inúmeras opções de carreira (Baruch, 2004), mobilizando, para tanto, guias internos, como crescimento pessoal e aprendizagem (Weick, 1996), em vez de externos, como hierarquia funcional e treinamento organizacional.

Em última instância, traduz-se como liberdade o fato de os "trabalhadores sem fronteiras" terem de planejar suas trajetórias profissionais e efetuarem as decisões referentes às suas qualificações e atuações profissionais. À superação das fronteiras relaciona-se a aquisição de uma multiplicidade de conhecimentos, matéria-prima para a construção de uma "carreira inteligente" (DeFillippi \& Arthur, 1994) composta por competências variadas - know-why (necessidades, motivação, valores, autoconhecimento e identificação), know-how (habilidades técnicas associadas ao ambiente de trabalho) e know-whom (capital social ou redes de contato externas e internas às organizações) -, tidas como elementos constitutivos do capital de carreira.

Esse arsenal de conhecimentos parece vincular-se aos conceitos de empregabilidade e de mobilidade, haja vista a alegação de que, diante de um quadro de crescente incerteza, complexidade e competitividade nos mercados, as empresas não poderiam mais se dar ao luxo de oferecer carreiras hierárquicas de longo prazo (Arthur \& Rousseau, 1996; Baruch, 2004). A noção de empregabilidade, que ganha projeção na década de 1990, atualiza a concepção tradicional de qualificação profissional, que deixa de ser uma atividade concentrada em um período da vida do trabalhador para se tornar um processo contínuo de treinamento, por intermédio do qual os indivíduos (re)constroem o seu capital de carreira. Subjacente a esse entendimento está a noção de que uma nova atitude diante do trabalho é esperada, atitude esta que vem modificando a concepção tradicional de carreira, até então associada a uma trajetória profissional linear e ascendente, normalmente desenvolvida no âmbito de uma organização e sob a sua tutela. Nesse sentido, a carreira passa a ser uma construção eminentemente individual, marcada por uma sucessão de escolhas autônomas do trabalhador, que pressupõe a passagem por diferentes organizações, daí seu caráter "sem fronteiras" (Bridges, 1995; Lemos, Rodriguez \& DeMonteiro, 2011).

A relevância atribuída à dimensão subjetiva de carreira reflete a ressignificação do contrato psicológico (Robinson, Kraatz, \& Rousseau, 1994); anteriormente pensado em termos de um conjunto de expectativas mútuas que refletiria a lealdade do trabalhador em troca de oportunidades de carreira e de estabilidade no emprego, o contrato psicológico nas últimas décadas expressaria um caráter não mais relacional, mas transacional (Mirvis \& Hall, 1994). A partir de então, desempenho e empregabilidade são propostos como as novas bases de troca das relações, agora de curto prazo, entre patrão e empregado.

Propõe-se, assim, um novo padrão normativo segundo o qual os indivíduos, despojados dos tradicionais critérios objetivos de sucesso, passam a privilegiar o balanceamento entre as esferas pessoal e profissional, os múltiplos comprometimentos (família, comunidade e trabalho) e a persecução de metas "pessoalmente significativas" (Mirvis \& Hall, 1994, p. 366). Ainda em linha com esse discurso, os indivíduos, por conta e risco de suas ações, comportamentos e motivações pessoais, podem ver-se libertos das amarras organizacionais e, consequentemente, das estruturas burocráticas de controle. 
Carreiras sem fronteiras e seus críticos

Desde a sua concepção, as carreiras sem fronteiras têm recebido inúmeras críticas que enfatizam, entre outros aspectos, a imprecisão e a ambiguidade da sua definição (Zeitz, Blau, \& Fertig, 2009), atribuídas, ao menos parcialmente, ao fato de sua criação não estar relacionada à constatação empírica de um fenômeno, mas à difusão acrítica de uma terminologia adotada no ano de 1993 como tema de conferência da Academy of Management (Inkson et al., 2012).

A denominação em si parece ignorar o fato de que, ao longo de suas carreiras, os indivíduos tendem a cruzar diversas barreiras, representadas, entre outros aspectos, por mudanças de função, de indústria ou setor de atuação e de localização geográfica (Inkson et al., 2012). Em lugar da alegada supressão das fronteiras organizacionais, aponta-se para a sua maior permeabilidade. Destaca-se, igualmente, que o enfraquecimento dos vínculos com as organizações corresponde ao fortalecimento de outros comprometimentos, expressos, por exemplo, pela redução da mobilidade ocupacional (Walton \& Mallon, 2004; Currie, Tempest, \& Starkey, 2006; Lawrence, 2010).

Nem mesmo o incremento da mobilidade interorganizacional é ponto pacífico na literatura. Via de regra, esse fato é associado à deterioração das condições tradicionais de emprego, reflexo dos crescentes níveis de segurança e instabilidade no mercado de trabalho. Todavia, estudos que se debruçam sobre o tema tendem a refletir pequenas alterações no giro da mão de obra nas últimas décadas, contrapondo-se às alegações que defendem a superação da carreira organizacional em favor da emergência e dominância das carreiras sem fronteiras (Inkson et al., 2012; Clarke, 2013).

Outra crítica recorrente diz respeito às reduzidas evidências empíricas capazes de suportar as mudanças associadas ao construto carreiras sem fronteiras (Cohen \& Mallon, 1999; Pringle \& Mallon, 2003). As prescrições subjacentes a tal perspectiva tem como suporte primordial os resultados de pesquisas cujo foco de análise recaiu sobre empresas inseridas em subsetores específicos e com dinâmicas muito particulares de funcionamento, a exemplo das indústrias de alta tecnologia do Vale do Silício (Saxenian, 1996), de filmes (Jones, 1996) e de biotecnologia (Eaton \& Bailyn, 2000).

O destaque conferido ao papel da agência no delineamento das carreiras sem fronteiras (Weick, 1996; Eby, Butts \& Lockwood, 2003) é julgado excessivo por críticos que veem, nesse movimento, um argumento que visa legitimar a transferência do ônus do desenvolvimento integral da carreira para o trabalhador (Pringle \& Mallon, 2003) que, enquanto empresário de si mesmo, é assumido como capaz de negociar, livremente, o seu passe no mercado.

A crescente relevância atribuída à dimensão contextual de análise (Mayrhofer, Meyer \& Steyrer, 2007; Sullivan \& Baruch, 2009) permite a consideração de aspectos pouco abordados pelos defensores do construto carreiras sem fronteiras, afeitos sobremaneira ao contexto imediato de análise. O reconhecimento da influência das dimensões política e social no processo de construção de carreiras é sugerido como forma de viabilizar a compreensão do impacto dos condicionantes sociais nas trajetórias profissionais, desvelando, assim, "como o conceito de 'carreira', e os padrões de carreira de uma dada ocupação refletem as diferenças entre indivíduos com diferentes origens sociais" (Gunz, Mayrhofer \& Tolbert, 2011, p. 1614).

A extensão das carreiras sem fronteiras a "todos os trabalhadores e a todas as sequências de trabalhos" (Arthur \& Rousseau, 1996) é igualmente questionada por desconsiderar, entre outros aspectos, diferenças interculturais. A assunção da "portabilidade cultural" representaria, em última análise, a universalização de trajetórias de carreiras de um seleto grupo de trabalhadores white collar dos EUA (Walton \& Mallon, 2004, p. 92), refletindo, assim, manifestações de uma cultura marcada pelo individualismo (Chudzikowski Demel, Mayrhofer, Briscoe, Unite, Milikic, Hall, Las Heras, Shen, \& Zikic, 2009). Essa crítica é referendada por pesquisas realizadas em diferentes países, tais como Nigéria (Ituma \& Simpson, 2009), Bélgica (Vansteenkiste, Verbruggen \& Sels, 2013; De Caluwé, Van Dooren, Delfarotry, \& Janvier, 2014) e Tanzânia (Hanchey \& 
Berkelaar, 2015). Nota-se, portanto, a existência de “'obstáculos' ou fronteiras para uma carreira sem fronteiras" (Sullivan \& Baruch, 2009, p. 1553), derivadas, entre outros aspectos, de particularidades atribuídas a diferenças culturais (Pang, 2003). Alguns críticos argumentam que a normalização do construto carreiras sem fronteiras teria o condão de suprimir diferenças de toda ordem, ocultando barreiras impostas aos indivíduos em virtude de seu contexto de origem (Inkson et al., 2012) e de suas identidades étnica e de gênero (Pringle \& Mallon, 2003).

Em revisão de literatura que contemplou sobretudo as modalidades de carreira emergentes nas décadas de 1990 e 2000, Sullivan e Baruch (2009, p. 1550) constataram que poucos foram os estudos que focaram enquanto sujeitos de pesquisa aqueles indivíduos que "não obtiveram sucesso neste ambiente de trabalho não tradicional, global, orientado tecnologicamente", destacando ainda que, usualmente, aspectos negativos associados a tais modalidades, com destaque para as carreiras sem fronteiras, não são alvo de análise pelos pesquisadores deste campo, os quais tendem a focar as trajetórias de sucesso, usualmente ascendentes, potencialmente propiciadas por tais carreiras e pelos novos tempos. Assim, a reificação de uma modalidade de carreira assentada sobre conceitos como autogestão corresponderia, em larga medida, a um recorte de pesquisa que privilegia uma parcela ínfima de trabalhadores com acesso, ao longo de sua história de vida, a recursos escassos de ordem econômica, cultural e social. Cabe observar, contudo, que, para "aqueles menos favorecidos que lutam para mobilizar os recursos pessoais necessários para se engajar no mercado de trabalho eficazmente, a autogestão de carreira pode ser prejudicial" (King, 2004, p. 130).

Alguns autores, elevando o tom das críticas, sugerem que as carreiras sem fronteiras constituem-se tanto como uma forma de legitimação dos efeitos das reestruturações organizacionais e da redução das oportunidades de carreiras oferecidas atualmente no mercado (Cohen \& Mallon, 1999), quanto como uma "manifestação de um discurso neoliberal que enfatiza a responsabilidade individual e não organizacional ou societal pelos resultados econômicos e de carreira" (Roper, Ganesh \& Inkson, 2010, p. 673). No presente ensaio, também analisamos as carreiras sem fronteiras como um discurso que vem servindo para legitimar a atual etapa do capitalismo; contudo, elegemos o arcabouço teórico proposto por Boltanski e Chiapello (2009) para discutir criticamente o construto em questão. Em linha com a argumentação de Chiapello e Fairclough (2002), assumimos que o espírito do capitalismo corresponde a um "Discurso com 'D' maiúsculo" que pode ser analisado como uma "configuração de discursos ('d' minúsculo)", entre os quais destacamos a metáfora das carreiras sem fronteiras (Inkson, 2006), estrutura privilegiada de mediação entre organizações e indivíduos (Barley, 1989).

\section{Carreiras sem fronteiras: libertação das amarras ou sujeição irrestrita às demandas organizacionais?}

O quadro teórico proposto por Boltanski e Chiapello (2009) forneceu a lente analítica por meio da qual discutiremos, nesta seção, a emergência do construto carreiras sem fronteiras. A extensa análise apresentada pelos autores acerca do discurso gerencial aborda conceitos fundamentais à ressignificação do trabalho na atual etapa do capitalismo, mas não chega a fazer alusão ao conceito de carreiras sem fronteiras. Ao contrário, os autores afirmam que na "cidade por projetos" os trabalhadores não fariam carreira. Argumentamos que uma atenção especial deve ser dedicada a esse construto por entendermos que ele descreve, de forma exemplar, a carreira do trabalhador apto a transitar na "cidade por projetos". Nesse sentido, postulamos que a enunciação positiva dessa nova perspectiva vem contribuindo, à semelhança de construtos como empregabilidade e flexibilidade, discutidos por Boltanski e Chiapello (2009), para a construção do novo espírito do capitalismo.

Ao descreverem as condições de reestruturação do capitalismo nas últimas décadas do século XX, os autores destacam que "o capitalismo mundial... vai muito bem. Quanto às sociedades... não vão nada bem" (Boltanski \& Chiapello, 2009, p. 23). Os dados referentes ao crescimento do desemprego, subemprego e empobrecimento da população na Europa e nos Estados Unidos reforçam o argumento de que, para seguir mantendo o engajamento da força de trabalho - notadamente dos integrantes das "classes médias" -, o 
sistema capitalista precisa de dispositivos capazes de ressignificar a precarização que marca as relações de trabalho nas últimas décadas. É sob essas circunstâncias, que se concebe a construção discursiva que enuncia as virtudes das carreiras sem fronteiras como um importante recurso ideológico capaz não só de atualizar o conceito de carreira, mas também de associar um sentido positivo - e mesmo "libertador" - à precariedade subjacente à necessidade de mobilidade organizacional frequente, atualmente requerida pelo capitalismo.

Ao criticarem as atuais condições de mobilização da força de trabalho, Boltanski e Chiapello (2009, p. 28) chamam atenção para o "fatalismo atualmente dominante, que apresenta as mudanças recentes como mutações inevitáveis, mas benéficas no longo prazo". Em linha com essas considerações, argumentamos que o discurso subjacente ao conceito de carreiras sem fronteiras conjuga esses dois elementos: o fatalismo das mudanças - 0 anunciado fim das carreiras organizacionais - e o otimismo quanto a seus desdobramentos futuros - expresso na "liberdade" conquistada pelo profissional sem fronteiras.

Argumentamos que alguns dos principais pontos de aproximação entre o discurso sobre as carreiras sem fronteiras e o discurso sobre o terceiro espírito do capitalismo (Chiapello \& Fairclough, 2002) são a defesa da autonomia como valor inquestionável, a ênfase na empregabilidade como condição imprescindível para o trânsito entre as diferentes organizações e a valorização da mobilidade ocupacional. Os tópicos seguintes buscam discutir estes pontos.

\section{Autonomia conquistada?}

Ao retratarem o discurso empresarial dos anos 1990, manifesto na literatura de gestão empresarial, da qual os trabalhos sobre o construto carreiras sem fronteiras são parte integrante, Boltanski e Chiapello (2009) destacam a crítica que aquela literatura faz às estruturas burocráticas, por restringirem a autonomia dos trabalhadores. De acordo com os autores, a configuração ideológica do discurso empresarial tem a função de criar uma representação da empresa e fornecer argumentos capazes de mobilizar a força de trabalho, notadamente seus integrantes mais qualificados, em prol da melhoria do desempenho. Ressaltamos, inicialmente, que a literatura dedicada a descrever as carreiras sem fronteiras é exitosa nesse papel ideológico, ao elogiar a libertação dos trabalhadores das pesadas estruturas hierárquicas organizacionais, ao mesmo tempo em que valoriza a autonomia supostamente conquistada (Baruch, 2004; Baruch \& Reis, 2016). Mais do que descrever um novo status quo, essa produção discursiva constrói um novo status quo, na medida em que prescreve atitudes e comportamentos para aqueles que desejam transitar com êxito por um mundo do trabalho retratado como "sem fronteiras" ou, nos termos de Boltanski e Chiapello (2009), na "cidade por projetos".

Destinada, sobretudo, a executivos e profissionais com formação superior, essa literatura confere um significado virtuoso à efemeridade dos vínculos que vêm sendo construídos pelos indivíduos com as organizações. A precariedade subjacente a essa nova condição é ressignificada como "conquista de autonomia" (Baruch \& Reis, 2016). Em oposição à lealdade valorizada pelo segundo espírito, o trabalhador sem fronteiras deve prezar o fato de ser "autônomo" e estar liberto das amarras das carreiras burocráticas tradicionais.

A promessa de libertação, um dos principais atrativos desse discurso segundo Boltanski e Chiapello (2009), é, não por acaso, central na descrição dos ganhos decorrentes da possibilidade de construir uma carreira sem fronteiras. Nesse sentido, como foi apontado na introdução do presente artigo, essa possibilidade sinaliza a ruptura com a "dependência dos empregados da empresa empregadora" (Arthur \& Rousseau, 1996, p. 7). A autonomia em relação às organizações, todavia, implica que os trabalhadores se responsabilizem pela gestão da própria carreira, deixando de contar com a tutela organizacional de suas trajetórias profissionais. Trata-se, portanto, de uma "libertação" que não dá ao "liberto" outra opção além da responsabilização integral pelo sucesso e/ou fracasso da sua própria trajetória. 
Em busca da empregabilidade

A alegada libertação da tutela, no entanto, impõe outros custos aos indivíduos, que perdem as garantias erigidas na construção do segundo espírito, tais como a progressão meritocrática na carreira organizacional e a relativa segurança no emprego (Boltanski \& Chiapello, 2009). Novamente entra em cena a releitura positiva dessas perdas, presente na literatura sobre as carreiras sem fronteiras, que as transmuta em oportunidades de crescimento ilimitadas, expressão de autonomia e resiliência individual. Mas, para que essas novas oportunidades se realizem, essa mesma literatura deixa claro que a conquista da empregabilidade é mandatória para o profissional que deseja transitar por diferentes organizações, de forma a aproveitar as oportunidades que se apresentam. Apesar de, segundo Arthur e Rousseau (1996), a modalidade carreiras sem fronteiras ser o novo status quo, cabe destacar que a adaptação a essa realidade não acontece sem custo para os trabalhadores nem, muito menos, é acessível a todos. Concepção intrinsecamente elitizada, a empregabilidade apresenta-se como requisito para a circulação exitosa entre as diversas fronteiras organizacionais.

Direcionado sobretudo aos executivos e candidatos às posições no topo da hierarquia organizacional, o discurso da empregabilidade apresenta-se como a possibilidade de construção de uma nova trajetória heroica para aqueles que reúnem as competências requeridas para transitar entre diferentes "projetos". Retratado como empresário de si mesmo, desse ator é demandada a capacidade de gerir e investir em sua carreira, fazendo-se atraente aos olhos das empresas, cada vez mais seletivas e efêmeras em suas contratações (Arthur \& Hall, 1996; Mirvis \& Hall, 1996; Inkson et al., 2012). Conforme afirmam Boltanski e Chiapello (2009), apesar de ainda oferecerem perspectivas de carreiras a seus quadros mais talentosos, as empresas não oferecem mais garantias de longo prazo, o que faz com que mesmo os "escolhidos" tenham que estar permanentemente atentos a novas oportunidades em outras organizações. A busca da empregabilidade, emblemática do terceiro espírito, passa a ser, portanto, uma exigência permanente feita aos trabalhadores, que não podem se "acomodar" sob a pena de serem excluídos da disputa pelas decrescentes oportunidades de trabalho. Ao responsabilizar os trabalhadores integralmente pelo sucesso ou fracasso na obtenção de uma posição no mercado de trabalho, o discurso que valoriza a suposta autonomia, subjacente aos construtos empregabilidade e carreiras sem fronteiras, desconsidera os condicionantes estruturais que restringem as oportunidades de trabalho na atual etapa de acumulação capitalista.

Por pressupor a capacidade de os indivíduos tomarem para si a gestão de suas carreiras e de sua capacitação profissional (Arthur \& Hall, 1996; Mirvis \& Hall, 1994), o conceito de carreiras sem fronteiras traz implícita a demanda por um comportamento alinhado ao prescrito para se transitar na "cidade por projetos" (Boltanski \& Chiapello, 2009), metáfora que expressaria a ideologia e os valores do terceiro espírito do capitalismo. Argumentamos, portanto, que o trabalhador sem fronteiras personifica esse terceiro espírito, por sua capacidade de transitar entre diferentes projetos, funções e organizações. Esta capacidade faz com que ele represente a "grandeza" desse espírito, encarnando os traços de autonomia, assunção de risco e flexibilidade que passam a ser demandados.

Trânsito entre empresas como medida de sucesso

Diferentemente de seus antecessores, que personificavam o segundo espírito, o trabalhador que encarna o terceiro espírito não deve esperar construir um vínculo organizacional duradouro; valoriza, em vez disso, o trânsito entre diferentes projetos. A medida de seu sucesso não é mais a ascensão organizacional vertical, mas a facilidade com que se engaja, sucessivamente, em novos projetos. Assim, a carreira sem fronteiras se apresenta como a carreira possível a ser trilhada pelo trabalhador contemporâneo e a permanência em uma organização por um longo período passa a representar algo indesejável. 
Boltanski e Chiapello (2009) destacam que a proposta de participação em sucessivos projetos é apresentada como possibilidade de libertação da estrutura burocrática e da autoridade do chefe subjacente ao terceiro espírito do capitalismo, tão reivindicada pelos executivos, pois, se as trajetórias profissionais passam a ter por base características como criatividade, reatividade e flexibilidade, "ninguém mais está limitado pela seção à qual pertence nem totalmente submetido à autoridade de um chefe, pois todas as fronteiras podem ser transpostas pela virtude dos projetos" (Boltanski \& Chiapello, 2009, p. 122). Esta noção de libertação está também presente no discurso das carreiras sem fronteiras, ao ressaltar-se que o novo profissional está liberto das "amarras" organizacionais (DeFillippi \& Arthur, 1994).

De forma similar ao descrito acerca do trabalhador sem fronteiras (DeFillippi \& Arthur, 1994), a proposta de desenvolvimento pessoal da nova forma de organização por projetos exige um número maior de habilidades - profissionais e pessoais - e um nível maior de capacitação das pessoas. Esse novo modelo, explicam Boltanski e Chiapello (2009, p. 122), "propõe uma 'verdadeira autonomia'... baseada num autoconhecimento e na realização pessoal, e não a falsa autonomia, delimitada pela trajetória da carreira, por definições de função e por sistema de punições-recompensas, propostos nos anos 60".

Contudo, Boltanski e Chiapello (2009) tecem uma crítica a essa garantia, uma vez que a empregabilidade é um conceito de difícil mensuração, especialmente quando comparado à administração por objetivos, utilizada para medir o desempenho do trabalhador. Em linha com as considerações dos autores, postulamos que a possibilidade de transitar entre diferentes organizações, anunciada como conquista do trabalhador sem fronteiras, é sobretudo um peso depositado em seus ombros, posto que traz implícita a ideia de que o insucesso na obtenção de uma nova colocação seria decorrente da falta de preparo ou de capacidade de articulação desse trabalhador.

Os autores também afirmam que a ideia de empregabilidade se apresenta como incapaz de oferecer garantias ao trabalhador para que este se engaje no projeto capitalista (Boltanski \& Chiapello, 2009). De forma semelhante, o apelo à ética pessoal como garantia de lealdade do executivo à empresa não apresenta consistência capaz de assegurar o empenho individual. É possível, portanto, afirmar que o novo espírito do capitalismo oferece menos segurança - ou ao menos uma garantia menos sólida - para o trabalhador.

Cabe destacar, todavia, que a crítica ao construto carreiras sem fronteiras não implica a idealização do segundo espírito do capitalismo, tampouco a defesa das carreiras tradicionais ou hierárquicas que o caracterizavam. Conforme destacam Boltanski e Chiapello (2009), a cada momento histórico, o capitalismo demanda recursos ideológicos capazes de justificar a adesão da força de trabalho ao sistema produtivo. Nesse sentido, as carreiras tradicionais foram, à sua época, a expressão do êxito prometido aos trabalhadores que se engajaram no projeto capitalista, expresso no segundo espírito e, à semelhança do construto carreiras sem fronteiras, se mostraram representativas de um modelo aplicável tão somente a uma minoria de trabalhadores (Barley, 1989).

\section{Considerações finais}

Dados do mercado de trabalho brasileiro nos últimos anos refletem uma realidade dissonante daquela que associa as carreiras atuais ao crescimento de postos de trabalho altamente qualificados (Baruch, 2004), calcados no desenvolvimento de múltiplas competências (DeFillippi \& Arthur, 2004). Em contraposição aos argumentos que enfatizam a dominância das carreiras sem fronteiras na atualidade (Arthur \& Rousseau, 1996), a metamorfose do trabalho verificada no contexto brasileiro recente pode ser caracterizada pela combinação de um duplo movimento; por um lado nota-se a geração de um vasto contingente de posições mal remuneradas, por outro evidencia-se a supressão de vagas de trabalho com melhores salários. Segundo Pochmann (2012), dos cerca de 21 milhões de postos de trabalho gerados na década de 2000, aproximadamente 20 milhões, ou $95 \%$ do total, são de baixa qualidade e remuneraram na faixa de até 1,5 salário mínimo. Ademais, a geração 
de postos de trabalho nessa faixa de renda entre as décadas de 1980 e 1990 foi da ordem de $15 \%$, o que revela um crescimento expressivo da participação relativa dos postos de menor remuneração no contingente total de vagas criadas no período. Por outro lado, na década de 2000, foram suprimidas 4 milhões de posições com ganhos superiores a 3 salários mínimos, ao passo que nas duas décadas anteriores foram criados 5,4 milhões de postos nessa faixa de renda.

Assim, ainda que a emergência das carreiras sem fronteiras venha sendo festejada como um mecanismo que simboliza a superação de um "legado Orwelliano de ideias interdependentes acerca do domínio de grandes formas burocráticas de organização que permaneceram sem contestação até a passagem simbólica de 1984" (Arthur \& Rousseau, 1997, p. 7), são muitas as evidências que não se coadunam com este diagnóstico. Conforme buscamos discutir neste artigo, o que se percebe, ao longo dos últimos anos no campo de estudos de carreira, é o avanço de uma retórica cujo pilar central é a mobilização de uma nova gramática que, em seu conjunto, sugere a existência de uma profunda ruptura estrutural sem, no entanto, tematizar aspectos relevantes como a existência de vencedores e perdedores nesta nova etapa do sistema capitalista, a continuada relevância das barreiras nas trajetórias profissionais atuais e os problemas sociais emergentes (Hirsch \& Shanley, 1996), sobretudo a crescente precarização do mundo do trabalho (Boltanski \& Chiapello, 2009).

Interessante notar que esta nova gramática ecoa a nova fala ou "novilíngua" de George Orwell (2016), buscando superar o vocabulário dominante até a década de 1990, ao mesmo tempo em que promove a crítica dos sistemas econômico, organizacional e de trabalho correspondente. Em vez de contextualizar eventuais mudanças verificáveis no cenário atual, os proponentes dessa nova modalidade de carreira prescrevem um modelo de trajetória profissional em linha com a emergência de uma alegada nova era organizacional (Arthur \& Rousseau, 1996). Suprimem da análise as carreiras que representam a vasta maioria dos postos de trabalho da atualidade; em contrapartida, reificam modelos de carreira (Evetts, 1992) que privilegiam ocupações de trabalhadores das classes privilegiadas das economias do Ocidente (Dries, 2011; Hanchey \& Berkelaar, 2015). O custo, portanto, da ênfase irrestrita em premissas monoculturais é a exclusão consciente da análise das carreiras não só dos grupos não dominantes, mas também dos indivíduos que, independentemente da sua posição social, optam por seguir trajetórias profissionais que "não coincidem com as experiências, interesses e aspirações" legitimadas (Gabor \& Buzzanell, 2012). A operacionalização do processo de vaporização do passado - para falar com Orwell (2016) -, levada a cabo pela supressão de uma dada gramática pela sua antítese, traz consigo a invisibilidade de um conjunto maciço de indivíduos desta literatura sobre carreiras.

Diante de um cenário de crescimento de postos precários e de redução de direitos dos trabalhadores, é difícil vislumbrar quaisquer traços de um presente ou futuro reluzente. Postulamos, portanto, que o momento atual parece propício para reflexões sobre os efeitos da disseminação de modelos e conceitos exógenos que se revelam incapazes de retratar o cenário contemporâneo do trabalho, sobretudo em contextos periféricos. Nesse sentido, não é fácil antever - exceção feita a uma minoria de profissionais altamente qualificados - um futuro do trabalho auspicioso, no qual a dissolução das fronteiras organizacionais traga mais ganhos do que perdas.

\section{Referências}

Antunes, R. (2011). Adeus ao trabalho? Ensaio sobre as metamorfoses e a centralidade no mundo do trabalho. São Paulo: Cortez.

Arthur, M. B. (1994). The boundaryless career: A new perspective for organizational inquiry. Journal of Organizational Behavior, 15(4), 295-306.

Arthur, M. B., Claman, P. H., \& DeFillippi, R. J. (1995). Intelligent enterprise, intelligent careers. Academy of Management Executive, 9(4), 7-20. 
Arthur, M. B., \& Rousseau, D. (1996). The boundaryless career as a new employment principle. In M. B. Arthur \& D. Rousseau (Eds.). The boundaryless career: A new employment principle for a new organizational era (pp. 3-20). New York: Oxford University Press.

Ashkenas, R., Ulrich, D., Jick, T., \& Kerr, S. (1995). The boundaryless organization: Breaking the chains of organizational structure. San Francisco: Jossey-Bass Inc.

Baker, T., \& Aldrich, H. E. (1996). Prometheus stretches: Building identity and cumulative knowledge in multiemployer careers. In M. B. Arthur \& D. M. Rousseau (Eds.). The boundaryless career: A new employment principle for a new organizational era (pp. 132-149). New York: Oxford University Press.

Barley, S. R. (1989). Careers, identities, and institutions: The legacy of the Chicago school of sociology. In M. B. Arthur, D. T. Hall, \& B. S. Lawrence (Eds.). Handbook of career theory (pp. 41-65). Cambridge: Cambridge University Press.

Baruch, Y. (2004). Transforming careers: From linear to multidirectional careers paths. Organizational and individual perspectives. Career Development International, 9(1), 58-73.

Baruch, Y.; Reis, C. (2016). How global are boundaryless careers and how boundaryless careers are global careers? Challenges and a theoretical perspective. Thunderbird International Business Review, 58(1), 13-27.

Bird, A. (1996). Careers as repositories of knowledge. In M. B. Arthur \& D. M. Rousseau (Eds.). The boundaryless career: A new employment principle for a new organizational era (pp. 150-168). Oxford: Oxford University Press.

Boltanski, L., \& Chiapello, È. (2009). O novo espírito do capitalismo. Martins Fontes: São Paulo.

Boltanski, L., \& Thévenot, L. (1991). De la justification. Les économies de la grandeur. Paris: Gallimard.

Boltanski, L., \& Thévenot, L. (1999). The sociology of critical capacity. European Journal of Sociology, 2(3), 359-377.

Bridges, W. (1995). Mudanças nas relações de trabalho. São Paulo: Makron Books.

Briscoe, J. P., \& Hall, D. T. (2006). The interplay of boundaryless and protean careers: Combinations and implications. Journal of Vocational Behavior, 69(1), 4-18.

Celikates, R. (2012). O não reconhecimento sistemático e a prática da crítica: Bourdieu, Boltanski e o papel da teoria crítica. Novos Estudos CEBRAP, 93, 29-42.

Chiapello, È., \& Fairclough, N. L. (2002). Understanding the new management ideology: A transdisciplinary contribution from critical discourse analysis and new sociology of capitalism. Discourse Society, 13(2), 185-208.

Chudzikowski, K., Demel, B., Briscoe, J. P., Unite, J., Milikic, B. B., Hall, D. T., Las Heras, M., Shen, Y., \& Zikic, J. (2009). Career transition and their causes: A country-comparative perspective. Journal of Occupational and Organizational Psychology, 82(4), 825-849.

Clarke, M. (2013). The organizational career: not dead but in need of redefinition. International Journal of Human Resource Management, 24(4), 684-703.

Cohen, L., \& Mallon, M. (1999). The transition from organizational employment to portfolio working: Perceptions of "boundarylessness". Work, Employment and Society, 13(2), 329-352.

Currie, G., Tempest, S., \& Starkey, K. (2006). New careers for old? Organizational and individual responses to changing boundaries. International Journal of Human Resource Management, 17(4), 755-774.

De Caluwé, C., Van Dooren, W. V., Delafortry, A., \& Janvier, R.. (2014). Mind-sets of boundaryless careers in public sector: The vanguard of a more mobile workforce. Public Personnel Management, 43(4), 490-519. 
DeFillippi, R., \& Arthur, M. (1994). The boundaryless career: A competency-based perspective. Journal of Organizational Behavior, 15(4), 307-324.

Dries, N. (2011). The meaning of career success: Avoiding reification through a closer inspection of historical, cultural, and ideological contexts. Career Development International, 16(4), 364-384.

Eaton, S., \& Bailyn, L. (2000). Career as life path: Tracing work and life strategies of biotech professionals. In M. Peiperl, M. Arthur, R. Gofee, \& T. Morris (Eds.). Career frontiers: new conceptions of working lives (pp. 177-198). Oxford: Oxford University Press.

Eby, L. T., Butts, M., \& Lockwood, A. (2003). Predictors of success in the era of the boundaryless career. Journal of Organizational Behavior, 24(6), 689-708.

Evetts, J. (1992). Dimensions of career: Avoiding reification in the analysis of change. Sociology, 26(1), 1-21.

Freitas, C. E. (2013). Boltanski, Taylor e Jessé Souza: No rastro sociológico da moralidade de classe no capitalismo. Revista Brasileira de Sociologia da Emoção, 12(36), 752-767.

Gabor, E., \& Buzzanell, P. M. (2012). From stigma to resistant career discourses: Toward a co-cultural career communication model for non-dominant group members. Intercultural Communication Studies, 21(3), $1-17$.

Gunz, H., Mayrhofer, W., \& Tolbert, P. S. (2011). Career as a social and political phenomenon in the globalized economy. Organization Studies, 32(12), 1613-1620.

Hanchey, J. N., \& Berkelaar, B. L. (2015). Context matters: Examining discourses of career success in Tanzania. Management Communication Quarterly, 29(3), 411-439.

Harvey, D. (1992). Condição pós-moderna: Uma pesquisa sobre as origens da mudança cultural. São Paulo: Loyola.

Higgins, M., Dobrow, S. R., \& Roloff, K. S. (2010). Optimism and the boundaryless career: The role of developmental relationships. Journal of Organizational Behavior, 31(5), 749-769.

Hirsch, P. M., \& Shanley, M. (1996). The rhetoric of boundaryless - or, how the newly empowered managerial class bought into its own marginalization. In M. B. Arthur \&, D. M. Rousseau (Eds.). The boundaryless career: A new employment principle for a new organizational era (pp. 208-233). Oxford: Oxford University Press.

Hirschhorn, L., \& Gilmore, T. (1992). The new boundaries of the "boundaryless" company. Harvard Business Review, May-June.

Inkson, K. (2006). Protean and boundaryless careers as metaphors. Journal of Vocational Behavior, 69(1), 48-63.

Inkson, K., \& Arthur, M. (2001). How to become a successful career capitalist. Organizational Dynamics, 30(1), 48-61.

Inkson, K., Gunz, H., Ganesh, S., \& Roper, J. (2012). Boundaryless careers: Bringing back boundaries. Organization Studies, 33(3), 323-340.

Ituma, A., \& Simpson, R. (2009). The 'boundaryless' career and career boundaries: Applying an institutionalist perspective to ICT workers in the context of Nigeria. Human Relations, 62(5), 727-761.

Jones, C. (1996). Careers in project networks: The case of the film industry. In M. B. Arthur, \& D. M. Rousseau (Eds.). The boundaryless career: A new employment principle for a new organizational era (pp. 58-75). New York: Oxford University Press.

Kanter, R. M. (1989). When giants learn to dance: Mastering the challenge of strategy, management, and careers in the 1990s. New York: Simon \& Schuster. 
King, Z. (2004). Career self-management: Its nature, causes and consequences. Journal of Vocational Behavior, 65(1), 112-133.

Lawrence, B. S. (2010). Careers, social context and interdisciplinary thinking. Los Angeles: California Center for Population Research. [On-Line Working Paper Series].

Lemos, A. H. C., Rodriguez, D. A., \& DeMonteiro, V. C. (2011). Empregabilidade e sociedade disciplinar: Uma análise do discurso do trabalho contemporâneo à luz de categorias foucaultianas. Organizações \& Sociedade, 18(59), 587-604.

Mayrhofer, W., Meyer, M., \& Steyrer, J. (2007). Contextual issues in the study of careers. In H. Gunz, \& M. Peiperl (Eds.). Handbook of career studies (pp. 215-240). California: Sage Publications.

Miles, R. E., \& Snow, C. C. (1996). Twenty-first century careers. In M. B. Arthur, \& D. M. Rousseau (Eds.). The boundaryless career: A new employment principle for a new organizational era (pp. 97-115). New York: Oxford University Press.

Mirvis, P. H., \& Hall, D. T. (1994). Psychological success and the boundaryless career. Journal of Organizational Behavior, 15(4), 365-380.

Orwell, G. (2016). 1984. São Paulo: Companhia das Letras.

Pang, M. (2003). Boundaryless careers? The (in-)voluntary (re-)actions of some Chinese in Hong Kong and Britain. International Journal of Human Resource Management, 14(5), 809-820.

Pochmann, M. (2012). Nova classe média? O trabalho na base da pirâmide social brasileira. São Paulo: Boitempo.

Pringle, J. K., \& Mallon, M. (2003). Challenges for the boundaryless career odyssey. International Journal of Human Resource Management, 14(5), 839-853.

Raider, H. J., \& Burt, R. S. (1996). Boundaryless careers and social capital. In M. B. Arthur, \& D. M. Rousseau (Eds.) The boundaryless career: A new employment principle for a new organizational era (pp. 187-200). Oxford: Oxford University Press.

Robinson, S. L., Kraatz, M. S., \& Rousseau, D. M. (1994). Changing obligations and the psychological contract: A longitudinal study. Academy of Management Journal, 37(1), 137-152.

Roper, J., Ganesh, S., \& Inkson, K. (2010). Neoliberalism and knowledge interests in boundaryless careers discourse. Work, employment and society, 24(4), 661-679.

Rosenbaum, J. E. (1979). Tournament mobility: career patterns in a corporation. Administrative Science Quarterly, 24(2), 220-241.

Saxenian, A. (1996). Beyond boundaries: Open labor markets and learning in Silicon Valley. In M. B. Arthur, \& D. M. Rousseau (Eds.). The boundaryless career: A new employment principle for a new organizational era (pp. 23-39). New York: Oxford University Press.

Sullivan, S. E., \& Arthur, M. (2006). The evolution of the boundaryless career concept: Examining physical and psychological mobility. Journal of Vocational Behavior, 69(1), 19-29.

Sullivan, S. E., \& Baruch, Y. (2009). Advances in career theory and research: A critical review and agenda for future exploration. Journal of Management, 35(6), 1542-1571.

Vandenberghe, F. (2015). Os pós-bourdieusianos: Retrato de uma família disfuncional. In F. Vandenberghe \&, J.-F. Véran (Orgs.). Além do habitus: Teoria social pós-bourdieusiana (pp. 27-36). Rio de Janeiro: 7 Letras.

Vansteenkiste, S., Verbruggen, M., \& Sels, L. (2013). Being unemployed the boundaryless career era: Does psychological mobility pay off? Journal of Vocational Behavior, 82(2), 135-143. 
Véran, J. F., \& Vandenbergue, F. (2015). Novas sociologias: Um exercício de teoria comparativa. In F. Vandenberghe, \& J.-F. Véran (Orgs.). Além do habitus: Teoria social pós-bourdieusiana (pp. 9-25). Rio de Janeiro: 7 Letras.

Walton, S., \& Mallon, M. (2004). Redefining the boundaries? Making sense of career in contemporary New Zealand. Asia Pacific Journal of Human Resources, 42(1), 75-95.

Weick, K.E. (1996). Enactment and the boundaryless career: Organizing as we work. In: M. B. Arthur, \& D. M. Rousseau (Eds.). The boundaryless career: A new employment principle for a new organizational era (pp. 40-57). New York: Oxford University Press.

Wilensky, H. L. (1964). The professionalization of everyone? American Journal of Sociology, 7(2), 137-158.

Zeitz, G., Blau, G., \& Fertig, J. (2009). Boundaryless careers and institutional resources. International Journal of Human Resource Management, 20(2), 372-398.

\section{Sobre os Autores}

\section{Filipe Augusto Silveira de Souza}

Professor do Departamento de Administração Geral e Recursos Humanos da Fundação Getúlio Vargas. Doutor em Administração de Empresas pela Pontifícia Universidade Católica do Rio de Janeiro. Email: filipe.souza@fgv.br e filipe.a.souza@ globo.com. ORCID: 0000-0001-7547-8947

\section{Ana Heloísa da Costa Lemos}

Professora do Programa de Pós-graduação em Administração de Empresas da Pontifícia Universidade Católica do Rio de Janeiro. Doutora em Sociologia pelo IUPERJ. Email: aheloisa@iag.puc-rio.br. ORCID: 000-0001-6222-6628

\section{Marcelo Almeida de Carvalho Silva}

Professor do Programa de Pós-graduação em Ciências Contábeis da Universidade Federal do Rio de Janeiro. Doutor em Administração de Empresas pela Pontifícia Universidade Católica do Rio de Janeiro. Email: marceloacs@facc.ufrj.br e marceloacs@hotmail.com. ORCID: 0000-0001-8970-1177 